\title{
RAZÃO DO PROCESSO E RAZÃO NO PROCESSO ${ }^{1}$
}

\section{REASON ON THE PROCESS AND REASON IN THE PROCESS}

\section{Lucas Cavalcanti da Silva}

Juiz de Direito do Tribunal de Justiça do Paraná (TJPR), Mestrando em direito pela Universidade Federal do Paraná (UFPR) e Especialista pela Academia Brasileira de Direito Constitucional (ABDConst). Curitiba/PR. E-mail: lucas_taubate@hotmail.com

RESUMO: Este artigo trata da relação entre o funcionamento do processo e a busca da verdade, entendida esta como a correspondência dos fatos nele anunciados com os fatos ocorridos no mundo. Ressalvando que o processo convive com limitações epistêmicas, o artigo defende que sua existência como meio para a afirmação do direito e participação dos interessados na definição de seus direitos demanda a verdade como ideal regulatório e exige que a atuação judicial seja pautada em critérios de racionalidade. Este trabalho também traz alguns exemplos, verificáveis no Código de Processo Civil, de disposições que espelham sua vocação correspondentista e racionalista.

PALAVRAS-CHAVE: Verdade. Correspondência. Racionalidade. Fatos. Justificação.

ABSTRACT: This article is about the relation between the functioning of the process and the search for the truth, understood as the correspondence of the facts announced with the facts that occurred in the world. Emphasizing that the process lives with epistemic limitations, the article argues that its existence as a means for the affirmation of the law and participation of those interested in defining their rights demands the truth as a regulatory ideal and requires that judicial action be based on rationality criteria. This work also brings

\footnotetext{
${ }^{1}$ Artigo recebido em 17/12/2020 e aprovado em 19/05/2021.
} 
some examples in the Code of Civil Procedure that reflect its correspondentist and rationalist vocation.

KEYWORDS: Truth. Correspondence. Rationality. Facts. Justification.

SUMÁRIO: 1. Introdução. 2. Verdade como ideal regulatório. 3. Razão do processo. 4. Razão no processo. 5. Razão do processo e razão no processo no CPC/15. 6. Conclusão. 7. Referências.

\section{INTRODUÇÃO}

A percepção de que o processo civil não é veículo de imposição da decisão do juiz independente de participação relevante das partes está consolidada, e tal posição é comum a qualquer visão que se adote de processo (mais inclinada ao perfil publicístico ou ao perfil privatístico). Não obstante, não parece totalmente clara na rotina forense a necessidade de que aquela participação não se esgote na simples oportunidade de manifestação, uma vez que pressupõe franca sindicabilidade das razões eleitas pelo juiz na construção de sua decisão, pois só assim as partes e as demais instâncias podem manusear os instrumentos legais para sua análise e controle.

O presente artigo busca apontar a importância da adoção da verdade - entendida como a correspondência entre os enunciados de fato e os acontecimentos no mundo - como fator de regulação da atividade dos atores do processo civil e norte para o exercício do raciocínio probatório do juiz. Este, de seu turno, é indicado como a atuação de uma racionalidade aberta à compreensão pelas partes e pelo público, sem que se dê peso ao subjetivismo do julgador, que embora sempre presente, não é só por si suficiente ou relevante.

As ideias deste trabalho são estruturadas tendo em vista a garantia fundamental da motivação das decisões judiciais, cujo conteúdo não sustenta decisionismos, mas exige que os elementos que devem influir na sua formação sejam encarados com racionalidade e objetividade. A estrutura do trabalho busca refletir a estrutura do Código de Processo Civil, formada por exigências de racionalidade do processo e no processo. 


\section{A VERDADE COMO IDEAL REGULATÓRIO}

"O segredo da verdade é o seguinte: não existem fatos, só existem histórias". A epígrafe do livro Viva o povo brasileiro, de João Ubaldo Ribeiro, chama a reflexão a respeito da ficção como companheira do real e da constatação inescapável de que a narrativa de fatos (ou histórias?) varia de acordo com a visão que o narrador tem do mundo.

A lição do imortal baiano também repercute no âmbito do processo. As partes constroem narrativas e sustentam subsunções de fatos a normas a partir de seus pontos de vista; mais do que isso, a partir de seus interesses.

Não obstante estas conhecidas dificuldades, defende-se uma concepção correspondentista de verdade como aquela que lhe traz melhor definição e que funciona de maneira mais adequada no processo. A verdade como correspondência é aquela que afirma que enunciados fáticos só serão verdadeiros se e somente se os fatos que descrevem tenham realmente ocorrido no mundo. Entende-se a correspondência como uma relação entre linguagem e mundo, entre afirmações (entidades linguísticas) e fatos (entidades extralinguísticas), havendo verdade quando uma expressão corresponde ao fato que diz respeito $^{2}$, e isto independente do conhecimento ou aceitação que os atores processuais têm a respeito deles.

O conceito correspondentista de verdade pressupõe um realismo epistemológico que se assenta na tese metafísica de pressupor que existe um mundo real independente do sujeito cognoscente e na tese gnoseológica, segundo a qual pode-se conhecer esse mundo real, ainda que de forma imperfeita ${ }^{3}$.

Este conceito se contrapõe ao conceito coerentista de verdade, para o qual a verdade de um enunciado consiste em seu pertencimento a um conjunto coerente de enunciados; assim, um enunciado, para ser verdadeiro, não tem que ser coerente com um conjunto de enunciados já definidos como verdadeiros, mas sim guardar concordância com todos os enunciados entre si. Tal teoria, entretanto, não supera o problema de que um conjunto de enunciados pode conter mais que um subconjunto coerente, e que a só coerência formal entre

TUZET, Giovanni. Filosofia della prova giuridica. 2. Ed. Torino: G. Giappichelli Editore, 2016. p. 71. ABELLAN, Marina Gascon. Los hechos en el derecho. Bases argumentales de la prueba. 3. Ed. Marcial Pons: Madri, 2010. p. 51. 
os enunciados permite que qualquer história, mesmo um conto de fadas, possa ser aceita como verdadeiras se formar um conjunto coerente, em um abandono do empirismo ${ }^{4}$.

De seu turno, a teoria pragmatista sustenta que a verdade de um enunciado é admitida em termos de "aceitabilidade justificada". Um enunciado é verdadeiro se está justificado crer que é verdadeiro, seja porque serve a algum fim ou porque é aceitável. Em outras palavras, um enunciado não está justificado porque é verdadeiro, mas é verdadeiro porque está justificado. A verdade, então, é o final da investigação ${ }^{5}$.

Segundo Marina Gascón Abellan, o problema desta teoria está em que, ao assimilar a verdade aos métodos de sua obtenção, fica condenada a abraçar um certo "relativismo ontológico", pois a realidade não seria algo dado, senão dependente de valores e teorias do agente, de esquemas de conhecimento ou verificação. Afinal, pode haver crenças "úteis" ou "satisfatórias", e que por isso se considere justificado aceitá-las, mas nem por isso deixariam de ser falsas ${ }^{6}$.

É preciso reconhecer, todavia, que o conceito correspondentista também convive com algumas dificuldades. Sustentar a busca da verdade como correspondência não pode ignorar questões como os limites que o ordenamento impõe a esta busca, a insuficiência de recursos epistêmicos e o próprio entendimento sobre verdade.

Mesmo Bentham, com sua ideia de "rectitude of decision", consagrada nos idos do século XIX, já admitia que o processo tem por finalidades, ainda que laterais, impedir violação a direitos e evitar altos custos e atrasos. Entretanto, para Bentham, o conflito entre

4 Ibidem, p. 52 e 53. Tem se admitido a coerência não como descrição da verdade, mas como critério de verdade, ou seja, um teste para aferição da verdade de uma narrativa ou probabilidade em questões de fato.

5 Ibidem, p. 55-56.

6 Além disso, segundo Giovanni Tuzet, a ideia de que "verdadeiro" é equivalente a "justificado" não estimula a pesquisa com a mesma força quando se é estimulado pela ideia da verdade como correspondência: "Inoltre, l'idea che "vero" equivalga a "giustificato" non stimola la ricerca con la stessa forza con qui questa è stimolata dall'idea che il vero non equivalga alle giustificazioni (anche le giustificazioni che ci sembrano più convincenti potrebbero rilevarsi erronee - si pensi ancora alle streghe o al sistema tolemaico)". (TUZET, Giovanni. Filosofia della prova giuridica. 2. Ed. Torino: G. Giappichelli Editore, 2016. p. 75).

7 Em linhas gerais, o "rectitude of decision" concerne à correta aplicação do direito e determinação rigorosa da verdade dos fatos passados, mediante avaliação racional da prova e do princípio segundo o qual não se pode vedar a produção ou excluir qualquer elemento de prova que, de alguma forma, seja relevante para a descoberta da verdade e a correção da decisão (the non-exclusion principle). 
os fins principais e laterais do processo deveriam ser resolvidos por critérios de utilitarismo, deixando claro que, para ele, é necessário dar peso maior à busca pela verdade ${ }^{8}$.

Atualmente, e não se precisa dizer muito a respeito, é consabido que o processo é adequado quando alcança um julgamento ótimo sobre os fatos e o Direito sem descuidar do respeito a outros valores, como a dignidade, intimidade, propriedade etc, que, por sua relevância, impõem certas restrições à atividade desenvolvida na busca pela verdade. Tratase da percepção de que os valores do processo não são orientados apenas ao seu resultado, temática bem trabalhada por Robert Summers ${ }^{9}$.

A razoável duração do processo (artigo $5^{\circ}$, LXXVIII, CF/88), com seus reflexos na lógica de funcionamento do procedimento (prazos, preclusão etc), também apresenta limitações ao alongamento de sua tramitação que a busca pela verdade poderia reclamar, dando peso à preocupação de que seu tempo fisiológico atinja perfil patológico. Lembra-se, também, da concepção da atividade probatória não só como movimento voltado à descoberta da verdade, mas também à redução e adequada distribuição do risco de erro a partir de decisões políticas ou morais acolhidas pela lei, que acaba por exigir standards de prova maior ou menor a depender da circunstância ${ }^{10}$.

É preciso admitir, por outro lado, que os fatos não são puramente empíricos, mas também combinam elementos de observação e de teoria (normativos e valorativos). Os

8 TWINING, William. Rethinking evidence. Exploratory essays. 2. Ed. Cambridge: Cambridge University Press, 2006. p. 41-43.

9 Bear in mind that various factors other than the process itself may contribute to good results. Indeed, these other factors may be exclusive causes. Sometimes it will be difficult to tell if a process feature contributes at all. But if a process feature contributes in significant measure to good results, it will have good result efficacy. The good result efficacy of a process feature makes the process good in that respect as a process. But this variety of process goodness must not be confused with process values. The goodness of good result efficacy derives from the goodness of process results. But process values are not result-oriented at all. (SUMMERS, Robert. S. Evaluating and improving legal process. A plea for process values. In Cornell Law Review. Vol. 60. Nov/1974. p. 16).

10 La discusión más interesante en este terreno es, sin embargo, la que se inicia hace algo más de una década, cuando se empieza a prestar atención sistemática a la distribución adecuada del riesgo de error al que queda siempre expuesta la decisión judicial sobre los hechos, dado su carácter inductivo y dados también los límites que a su reducción impone la consideración de los costes procesales. Como explica Laudan, se trata de um fin relativo al "control del error", lo que lo distingue de otros fines extrínsecos a la prueba, aunque no se refiere a su minimización sino a su distribución conforme "a uma decisión política según la cual cierto tipo de errores es peor, menos aceptable, que otros" en un determinado tipo de proceso (Laudan 2005: 97). De ahi que proponga calificarlo como un fin "quasi-epistémico". En un sentido semejante Alex Stein lo identifica como un "objetivo intrínseco" a la determinación de los hechos (2005: 1ss). (ACATINO, Daniella. Teoría de la prueba: ¿somos todos "racionalistas" ahora? Revus [Online], n. 39 Dezembro, 2019. p. 9). 
elementos de observação são sujeitos à falibilidade humana de todos os que intervém no processo, que precisam lidar, pois, com problemas de percepção ou de interpretação dos fatos $^{11}$; os elementos de teoria dependem dos conceitos e valores jurídicos, bem como da compreensão do julgador a respeito deles ${ }^{12}$.

Sem ignorar todas estas dificuldades encaradas pela concepção correspondentista de verdade, o que se afirma a partir dela é que o processo como busca da verdade é necessário para o Direito e para o bom funcionamento social, de modo que a busca pela verdade não pode ser considerada como valor inferior a outras escolhas políticas e morais, podendo conviver com elas. As dificuldades epistêmicas, oriundas das estruturas legais ou das limitações humanas, ao tempo em que não podem ser deixadas de lado, convidam à prudência e ao controle de nossas crenças, mas nem por isso inviabilizam pensar o processo a partir da exata congruência entre os fatos externos e seus enunciados trazidos aos autos.

Neste sentido, soa adequada a perspectiva de Giovanni Tuzet, segundo a qual a noção de verdade objetiva, ainda que "incognoscível" a linha que ligue um enunciado a um fato, serve como ideal regulatório, como critério conceitual básico que explica e justifica a busca por evidências. A verdade como ideal regulatório serve para o legislador, na identificação do método de avaliação; para o juiz, nas avaliações e escolhas discricionárias que esse método exige que ele faça; e para o cidadão, ao poder sindicar procedimentos e decisões consideradas injustas, ainda que esta guarde total congruência com todas as evidências obtidas no processo. Afirmar uma verdade objetiva serve como critério para configurar o processo e criticar seus resultados se eles forem baseados em avaliações incorretas. ${ }^{13}$

11 LAGIER, Daniel González. Apuntes sobre prueba y argumentacion jurídica. Disponível em <http://rua.ua.es/dspace/handle/10045/37145>. Acesso em 07 de julho de 2020, às 21:20h.

12 LAGIER, Daniel González. Tres modos de razonar sobre hechos (y algunos problemas sobre la prueba judicial planteados a partir de ellos). In VÁZQUEZ, Carmen. Hechos y razonamiento probatório. México DF: Editorial CEJI, 2018. A este respeito, aponta Susan Haack, citada por Atienza, que uma vez que os sistemas jurídicos são criações humanas, o que faz com que algo seja verdade juridicamente depende muito mais do que se cria do que propriamente do que se descobre (ATIENZA, Manuel. Pragmatismo jurídico: La propuesta de Susan Haack. p. 12). De seu turno, sustenta Marina Gascóna Abellán que tal circunstância não afasta a existência de um fato "bruto" e da necessidade de sua qualificação como fato antes de sua qualificação jurídica (ABELLAN, Marina Gascon. Los hechos en el derecho. Bases argumentales de la prueba. 3. Ed. Marcial Pons: Madri, 2010. p. 191-192).

13 TUZET, Giovanni. Filosofia della prova giuridica. 2. Ed. Torino: G. Giappichelli Editore, 2016. p. 7677. 
Como se pretende mostrar a seguir, a importância de uma concepção correspondentista da verdade denota-se da razão da existência do processo civil e de sua contribuição para a construção do Direito.

\section{A RAZÃO DO PROCESSO}

A lei apresenta por vezes conceitos fluidos e sua aplicação é reclamada a partir das idiossincrasias de cada pessoa interessada, de modo que o sentido da lei acaba sendo determinado pelo próprio Estado em sua atuação judicial. A lei, portanto, torna-se objeto de argumentação e é reconstruída a partir dela, de modo que, mais do que assegurar o respeito à lei formal, o Estado de Direito deve prestigiar o processo de argumentação que forja o sentido da lei ${ }^{14}$.

A construção da lei continua quando de sua interpretação e aplicação pelo juiz, em debate colaborativo com as partes. Vai daí que o processo não serve apenas para a solução de conflitos privados, porque suas decisões e conclusões a respeito do Direito objetivo têm o poder de se irradiar para além dos limites do processo ${ }^{15}$.

Este perfil publicístico do processo também revela sua importância para a segurança jurídica. Deveras, do ponto de vista externo, a segurança jurídica oferecida pelo processo civil está na cognoscibilidade do que poderá ser decidido por meio dele e na garantia de realização do direito material, ou seja, segurança de que o processo funcionará de maneira eficiente. É por meio do processo que o jurisdicionado poderá ter certeza do significado que

14 WALDRON, Jeremy. The rule of law and the importance of procedure. In. FELMING, J. Gettíng to the rule of law. New York: New York U. Press, Nomos, 2011. p. 18-20.

15 "Entretanto, em meu entendimento, o objetivo da adjudicação deve ser entendido de maneira mais ampla. A adjudicação utiliza recursos públicos e não emprega estranhos escolhidos pelas partes, mas agentes públicos escolhidos por um processo do qual o público participa. Esses agentes, como os membros dos Poderes Executivo e Legislativo, possuem um poder que foi definido e conferido pelo direito público e não por ajuste privado. Seu trabalho não é maximizar os objetivos de particulares, nem simplesmente assegurar a paz, mas explicar e conferir força aos valores contidos em textos de grande autoridade, como a Constituição e as leis: para interpretá-los e deles aproximar a realidade" (FISS, Owen. Contra o acordo. In: SALLES, Carlos Alberto de (coord.). Um novo Processo Civil: estudos norte-americanos sobre Jurisdição, Constituição e sociedade. Tradução Daniel Porto Godinho da Silva e Melina de Medeiros Rós. São Paulo: Editora Revista dos Tribunais, 2004. p. 139). 
o Estado empresta às normas jurídicas que regulam a sociedade de tal forma a pautar seu comportamento social ${ }^{16}$.

Nesse passo, não soa adequado que o processo seja encarado apenas como de interesse das partes litigantes de modo a se admitir que a sentença tenha como alicerce apenas as histórias (stories) contadas por elas, sem qualquer correspondência com o ocorrido no mundo dos fatos, ainda que com as limitações legais e humanas impostas na investigação desta correspondência. O princípio do dispositivo, ainda que assuma feição endoprocessual em alguns dos poderes processuais admitidos às partes, não deve alcançar o direito de dispor sobre a necessária correspondência entre fato e norma.

A partir disso, o grande desafio está em que o juiz não pode, tanto quanto possível, aceitar narrativas desassociadas do que aconteceu no mundo real. Como aponta Taruffo, o processo é método para apuração da verdade e, como instrumento de manifestação de poder do Estado e de consolidação do Direito, não pode se lançar a sustentar posições baseadas em algo distante do ocorrido efetivamente no mundo ${ }^{17}$.

É a partir do que efetivamente aconteceu no mundo dos fatos que se torna possível a identificação da norma jurídica aplicável à hipótese e, consequentemente, a identificação do seu sentido e alcance. Como já anotava Calamandrei, não se pode negar que a qualidade da sentença está diretamente relacionada com o grau de apuração que o juiz dedicou na investigação dos enunciados de fato $^{18}$.

16 OLIVEIRA, Paulo Mendes de. Segurança jurídica e processo. Da rigidez à flexibilização processual. São Paulo: RT, 2018. p. 118-130.

17 "As considerações precedentes, bem como as análises filosóficas nas quais essas se inspiraram, delineiam um quadro de uma situação sociopolítica na qual a verdade constitui um valor basilar de referência a um standard ao qual - mesmo que com inevitáveis exceções e limitações, que deveriam, entretanto, ser reduzidas ao mínimo - deveriam se conformar tanto com o Estado quanto com os cidadãos particulares [...] No contexto ético-político que assim se delineia, há sentido em colocar-se o problema sobre a existência do valor da verdade (e eventualmente sobre qual seja ele) no âmbito da administração da justiça. Prima facie caberia dizer que tal valor existe e é relevante. Por um lado, a administração da justiça constitui um setor importantíssimo da vida social e da atividade do Estado; desse modo, nessa dever-se-iam encontrar os próprios valores de verdade que constituem os critérios constitutivos do correto funcionamento do sistema sócio-político. Seria, por assim dizer, um tanto paradoxal imaginar um sistema democrático, inspirado no valor da verdade, no qual, entretanto, a administração da justiça não se inspirasse em tal valor, ou mesmo que se fundasse sistematicamente no erro, na mentira e na distorção da verdade". (TARUFFO, Michele. Uma simples verdade: o juiz e a construção dos fatos. Tradução de Vitor de Paula Ramos. São Paulo: Marcial Pons, 2016. p. 120-121).

18 non si puó tuttavia negare che nella gran maggioranza dei casi la bontà dela sentenza sta in diretta relazione col grado di acuratezza posto dal giudice nell indagare esattamente il rapporto di fatto. CALAMANDREI, Pietro. Opere giurdiche. Vol. 1. p. 25. Citado por OLIVEIRA, Carlos Alberto Alvaro de. Do formalismo no processo civil. 2. Ed. São Paulo: Saraiva, 2010. p. 9. 
A circunstância de o processo não ser lugar para cogitação de nada que se divorcie do conhecimento sobre o efetivamente acontecido não interessa apenas à forma como o juiz encara o discurso e a postura das partes, mas também à maneira pela qual estas recebem a atividade daquele.

Às funções processuais de construção do Direito e de garantia da segurança jurídica soma-se a de assegurar aos interessados na solução da controvérsia o direito de participação efetiva na construção da decisão. Não se concebe que o cidadão possa ter seu direito subjetivo definido pelo Estado-juiz sem que possa influir nessa definição, pois essa influência representa o próprio exercício do direito. A legitimidade da decisão construída ao final do procedimento - e, por consequência, a razão da existência do processo - passa pelo grau de participação do interessado e de quanto este pode influenciar na construção racional daquela decisão, no que se tem por justiça procedimental ${ }^{19}$.

Este espaço de participação das partes na definição dos destinos da relação jurídica que lhe diz respeito e de contribuição para a construção do Direito não tem qualquer relevância se, ao final, a decisão for radicada em subjetivismos não sindicáveis do julgador. O processo não é palco para que o juiz exponha suas opiniões pessoais e diga o direito ao caso concreto escudando-se na sua íntima convicção, como se esta fosse o ponto de partida legitimado pelas leis do processo ou por sua simples posição de autoridade. O raciocínio que embasa qualquer decisão do Estado deve estar sujeito à inspeção pública ${ }^{20}$, em controle do

19 Tanto en lo normativo como en la verificación de los hechos, las condiciones epistémicas para lograr la tutela del derecho sustantivo del caso pueden no ser perfectas, pero son - y debe exigirse lo sean - las mejores y posibles logradas que resulten aceptables. Con ello se suma la importância de la racionalidad de la decisión que como mínimos con lo razonable de su fundamentacion y motivacion. Por ello no es suficiente una explicación meramente procedimentalista que se contente solo con permitir la participación como necesaria y suficiente para la legitimidad del procedimiento que incluiria la decisión sin más. Ésta requiere de racionalidad en la que el resultado puede ser fundadamente explicado con un estándar de razonable. Así no es posible valorar solo lo decidido (el "después") sin el "antes" procedimental que garantiza la participación, como tampoco ex post solo conosiderar a ésta como suficiente para aceptar cualquiera sea lo decidido. La motivación así requiere: (i) los elementos estructurales del discurso que permitan establecer si se cumple o no la justiíicacion racional de validez y corrección;(ii) el contenido específico del discurso en el que se explicitan las elecciones. realizadas por el juzgador según las expectativas creadas durante el procedimiento y que tiene como destinatário a un auditorio amplio, no solo a los intervenientes (RAGONE, Álvaro Perez. El impaco entre lo sustantivo y lo procesal: el puente de la justicia procedimental. In: ARENHART, Sérgio Cruz; MITIDIERO, Daniel (coord.). O Processo civil entre a técnica processual e a tutela dos direitos: estudos em homenagem a Luiz Guilherme Marinoni. São Paulo: Editora Revista dos Tribunais, 2017. p. 32-33).

20 AARNIO, Aulis. Lo racional como razonable. Un tratado sobre la justificación jurídica. Madrid: Centro de Estudios Constitucionales, 1991. 
poder pelo saber, e esta inspeção é prejudicada se o Estado-juiz decide com base em circunstâncias de fato e de direito não demonstradas ou demonstráveis no campo do processo.

A justificação racional da decisão judicial não é só uma exigência técnica, mas fundamento da legitimidade do poder dos juízes, e deve estar presente desde o recebimento da primeira hipótese de fato até o apontamento final da qualificação valorativa e normativa dos enunciados constantes dos autos ${ }^{21}$.

Nessa ordem de ideias, o dever de fundamentação das decisões judiciais (art. 93, IX, da Constituição Federal), que assume contornos de garantia fundamental do cidadão, exige justificação idônea do magistrado na tomada de decisão, esta entendida como motivação amparada não em ideologia ou convicção subjetiva do juiz, mas em elementos concretos extraídos dos autos, verificáveis pelas partes e pelo público, a partir de critérios de racionalidade na análise dos fatos e das provas que lhe dizem respeito.

Importante destacar que a garantia de fundamentação das decisões judiciais só se faz plena quando o juiz também apresenta a justificativa a respeito dos enunciados fáticos que considera verdadeiros. Se atualmente o controle das razões de direito indicadas pelo juiz é facilitado pelo acesso rápido ao conteúdo das leis e da jurisprudência, em um sistema que se amolda cada vez mais ao respeito aos precedentes, é na aferição das razões sobre os fatos que o juiz exerce efetivamente seu poder. Bem por isso que o caminho de formação de convencimento também sobre os fatos deve ser motivado expressamente, sem o que se esvazia o conteúdo daquela garantia fundamental..$^{22}$

Esta necessária concepção racionalista do processo e da atividade judicial indica que o fato da valoração da prova ser declarada "livre" pelo direito significa apenas que esta

21 ABELLAN, Marina Gascon. Los hechos en el derecho. Bases argumentales de la prueba. 3. Ed. Marcial Pons: Madri, 2010. p. 169-183.

22 A garantia [da motivação das decisões judiciais] compreende não só o enunciado das escolhas do juiz em relação à individualização das normas aplicáveis ao caso concreto e às correspondentes consequências jurídicas, como os nexos de implicação e coerência entre esses enunciados, com vistas a possibilitar o controle do pronunciamento judicial pelas partes e pela sociedade (...) Cuida-se, ao fim e ao cabo, de balizar o poder do órgão judicial, bem capaz de se tornar exacerbado, principalmente em termos de apreciação dos fatos da causa, em vista do princípio do livre convencimento, largamente adotado nos sistemas processuais do século XX. Nesse quadro, a motivação assume realmente um papel fundamental de racionalização da valoração das provas, não afastada nem mesmo pela discricionariedade ínsita nesta, reclamando decisão jurisdicional sempre justificada de forma adequada. OLIVEIRA, Carlos Alberto Alvaro de. Do formalismo no processo civil. 2. Ed. São Paulo: Saraiva, 2010. p. 88-89. 
valoração não é regida pelas regras da prova legal ou tarifada que predeterminam o resultado probatório de forma vinculante para o juiz. Mas esta liberdade é limitada pelas regras gerais da epistemologia, da racionalidade e da lógica.

A razão da existência do processo, portanto, exige a presença da razão no processo, a partir da congruência da atividade jurisdicional com os parâmetros próprios da epistemologia.

\section{A RAZÃO NO PROCESSO}

A exigência de critérios de razão na fundamentação do processo, como já se disse, vai além da motivação da incidência das normas jurídicas pertinentes ao caso em julgamento, porque também alcança a justificação dos enunciados de fatos tidos por verdadeiros e relevantes para a decisão.

É importante lembrar, de início, que a relação entre fatos e normas não é de independência, mas de interdependência. Há uma espécie de simbiose entre fatos e normas, notadamente quando se lembra que o processo demonstra fatos não para simplesmente conhecê-los, mas para resolver controvérsias jurídicas; vale dizer, não se pretende determinar o fato em si mesmo, mas porque ele é pressuposto para a aplicação do direito. Não se pode falar de "fato" separando-o completamente do "direito" ou esquecendo de suas consequências jurídicas, assim como não se pode falar em estabelecimento da verdade dos fatos sem ter por base critérios jurídicos para sua investigação e qualificação. Não se quer dizer com isso que é possível confundir fato com direito, mas apenas que o fato não está dado por si mesmo e de forma autônoma antes de assumir relevância jurídica ${ }^{23}$.

Então, bem-vistas as coisas, a fundamentação jurídica da decisão judicial não prescinde da adequada fundamentação a respeito da existência dos fatos e das razões pelas quais estes assumem determinada qualificação jurídica. A fixação dos fatos, embora prévia, dialoga com sua qualificação jurídica. Vai daí que as provas produzidas pelos atores processuais não se prestam a convencer o juiz a adotar tal ou qual posição, mas, sim, precipuamente, a apontar para a correspondência dos enunciados de fato com aqueles fatos

\footnotetext{
${ }^{23}$ TARUFFO, Michele. La prueba de los hechos. Tradução para o espanhol de Jordi Beltran Ferrer. Madrid: Editorial Trotta, 2002. p. 90-92.
} 
que efetivamente aconteceram para que o juiz, em diálogo com as partes, promova sua adequada qualificação jurídica, indicando quais deles têm relevância para a construção da decisão.

Deveras, a prova não pode ser tida, só por si, como referência a uma situação pronta e acabada, não passível de discussão e com capacidade de trazer uma conclusão pronta ao juiz, que por isso exerceria um raciocínio puramente mecânico sobre seu conteúdo; a prova tampouco pode ser tida como mero elemento de retórica, servindo como uma racionalização "a posteriori" de uma escolha subjetiva do julgador a respeito de uma "melhor" versão dos fatos e do direito. A prova é voltada à aferição da verdade dos enunciados de fato, e não só como veículo de convencimento do juiz. Trata-se de conceber a prova como meio de certificação das hipóteses, e não como mero convencimento do juiz ${ }^{24}$.

A relação de proximidade entre fatos e direito e a percepção da prova como instrumento para construir uma decisão racional baseada nos fatos fazem possível concluir que: a) não há espaço para separação precisa entre apuração dos fatos e motivação da decisão; b) há traços em comum entre descobrimento (caminho para chegar a uma afirmação) e justificação (razões que justificam a afirmação), porque descobrir os fatos requer conhecimento e aceitação de suas hipóteses, e estes hão de $\operatorname{ser}_{\text {justificados }}{ }^{25}$; c) a avaliação racional e objetiva dos enunciados de fato apresentados pelas partes e das provas produzidas acompanham o juiz ao longo da estruturação da decisão, no exame individual de cada hipótese relevante, não o abandonando logo no seu ponto de partida, ou mesmo antes dele.

A primeira afirmação já foi trabalhada acima. A segunda tem por base a circunstância de que a aceitação da veracidade dos enunciados de fato deve ser devidamente justificada pelo juiz, senão em total congruência com seu iter psicológico, ao menos a partir da

24 "A concepção racionalista exige uma motivação não como uma explicação, mas como uma justificação em sentido estrito. Não importa, aqui, o iter psicológico e subjetivo do juiz, mas a motivação deve basear-se nas provas que justificam sua decisão. Passagem relevante da obra de Jordi Ferrer Beltrán para este trabalho reside na ideia de racionalidade teleológica e instrumental, de adequação de meios e fins, isto é, a racionalidade dos distintos métodos de valoração da prova e das distintas regras probatórias deve ser considerada a partir do fim perseguido pela atividade probatória no processo jurisdicional, vale dizer, a busca da verdade dos enunciados fáticos que descrevem os fatos juridicamente relevantes do caso". (MARANHÃO, Clayton de Albuquerque. Standards de prova no processo civil brasileiro. Revista Judiciária do Paraná, Curitiba, Vol. 17, p. 221-258. (Maio, 2019). p. 227).

${ }^{25}$ ABELLAN, Marina Gascon. Los hechos en el derecho. Bases argumentales de la prueba. 3. Ed. Marcial Pons: Madri, 2010. p. 100-101. 
Revista Eletrônica de Direito Processual - REDP.

Rio de Janeiro. Ano 16. Volume 23. Número 1. Janeiro a Abril de 2022

Periódico Quadrimestral da Pós-Graduação Stricto Sensu em Direito Processual da UERJ

Patrono: José Carlos Barbosa Moreira (in mem.). ISSN 1982-7636. pp. 814-834

www.redp.uerj.br

construção de argumentos que permitam sustentar um enunciado como verdadeiro. Tomar um enunciado de fato como verdade requer a adoção de métodos racionais de valoração da prova, verificáveis na decisão, capazes de depurar as percepções subjetivas do juiz, inaceitáveis que são como fundamentos da decisão.

O raciocínio probatório passa pela observação direta dos acontecimentos (situação rara) ou pela inferência dedutiva ou indutiva a partir das provas ou de outros enunciados tidos por verdadeiros. Passa, também, por uma exploração cuidadosa da relação entre as proposições ${ }^{26}$ e pela investigação sobre quando é possível admitir uma hipótese, dentre várias possíveis, como verdadeira (da prova à hipótese) e quando é justificado aceitar que a hipótese foi comprovada (da hipótese à prova), evitando raciocínios meramente circulares. ${ }^{27}$

Uma importante ressalva há de ser feita. Quando se trata de descoberta da verdade, notadamente a partir de métodos não-dedutivos, refere-se à formulação de juízos de probabilidade a respeito da correspondência do enunciado de fato com a verdade, já que não há caminhos epistêmicos para se chegar a uma conclusão irrefutável a respeito da ocorrência do fato e da veracidade de uma proposição. Como foi abordado na primeira parte deste trabalho, não há como deixar de se reconhecer as limitações do conhecimento humano e as dificuldades da fiel reprodução de fatos passados, mormente por pessoas que sequer deles $\operatorname{participaram}^{28}$.

26 [...] I am convinced that they are na excellent pedagogical device for a number of purposes: doing such exercises should drive home the lesson that analysis of evidence involves careful exploration of relations between propositions; it should help to make the student aware of the complexity of such relations and of the many possibilities of logical jumps and of fallacious reasoning when a mass of evidence is involved. (TWINING, William. Rethinking evidence. Exploratory essays. 2. Ed. Cambridge: Cambridge University Press, 2006., p. 20).

${ }^{27}$ Quello che è importante è che le prove con cui si cerca di verificare o falsificare un ípotesi - o almeno di rafforzala o indebolirla - siano altre prove rispetto a quelle da cui l'ípotesi è stata generata, a pena di circolarità del ragionamento. In altre parole, per testare un ípotesi si devono fare altre domande rispetto a quelle iniziali (TUZET, Giovanni. Filosofia della prova giuridica. 2. Ed. Torino: G. Giappichelli Editore, 2016. p. 129).

28 En segundo lugar, cuando se dice que la finalidad de la prueba es determinar la verdad de ciertos hechos (o afirmaciones sobre hechos), no se quiere decir que la prueba sea un procedimiento matemático que nos lleve a una verdad más allá de toda duda. La verdad empírica es siempre uma cuestión de probabilidad. Las afirmaciones sobre los hechos nunca constituyen una verdad absoluta, sino aproximada y graduable. Esto es así se tate de hechos históricos, geológicos, físicos, etc. La convicción que tenemos sobre ellos es graduable y puede llegar a ser muy alta, pero nunca es absoluta. Por tanto, lo que un razonamiento probatorio nos ofrece no es tampoco una certeza absoluta [...] A la luz de las anteriores consideraciones, parece claro que la certeza absoluta no puede exigirse como requisito necesario de la decisión judicial. Como ha señalado Asencio Mellado, la convicción del juez no puede entenderse "en términos de certeza absoluta, sino únicamente de probabilidad; se trata, pues, de un juicio de probabilidad, de mayor o menor acercamiento entre la afirmación y el hecho acaecido, y en tanto tal hecho no es conocido y es hecho 
Indo adiante, a justificação a respeito da admissão dos fatos verdadeiros pressupõe sua confirmação como tal e em maior grau do que qualquer outra hipótese, além de sua não refutação. A construção da justificação demanda o enfrentamento de todas as provas, mesmo as que não sejam utilizadas pelo juiz por confrontar a hipótese tida por certa, exatamente como teste para sua confirmação e não refutação.

É o que sustenta Jordi Ferrer Beltran ao propor um modelo de raciocínio probatório baseado na probabilidade indutiva eliminativa da hipótese ${ }^{29}$. Segundo o professor espanhol, é possível analisar e comparar as hipóteses apresentadas ao julgador por meio do grau de confirmação ou do suporte indutivo de cada uma delas, dando prevalência àquela com maior força, ou, para usar expressão de Taruffo, àquela com "probabilidade prevalecente". Não se fala aqui em probabilidade matemática ou em complementação entre as hipóteses (a afirmação de uma não é a negação de outra), mas sim em aumento da probabilidade da veracidade da hipótese a partir da superação de controles (meios de prova) concebidos para abalar ou confirmar sua fiabilidade.

Esta concepção de análise da probabilidade da veracidade de uma hipótese retoma a terceira conclusão acima exposta: a avaliação racional e objetiva dos enunciados de fato apresentados pelas partes e das provas produzidas acompanham o juiz ao longo da estruturação da decisão, no exame individual de cada hipótese relevante, não o abandonando logo no seu ponto de partida, ou mesmo antes dele.

A análise racional da prova refuta a ideia de valoração conjunta do acervo probatório, como se fosse suficiente apenas um olhar distante e genérico do juiz sobre todas as provas, em bloco, para dele eleger um caminho a seguir. A prática da valoração conjunta dos elementos de prova confere a uma decisão, quando muito, certa aparência de fundamentação, sem efetivamente fornecê-la, todavia.

Nessa ordem de ideias, tem-se sustentado a preponderância da concepção atomista à holística da decisão judicial. Enquanto a primeira defende que a decisão sobre o fato deve ser obtida de uma consideração analítica dos específicos elementos de prova, de seus respectivos valores probatórios e das específicas inferências que se fundam sobre cada um

pasado, la probabilidad ha de ser medida en términos de verosimilitud. (LAGIER, Daniel González. Apuntes sobre prueba y argumentacion jurídica. Disponível em <http://rua.ua.es/dspace/handle/10045/37145>. Acesso em 07 de julho de 2020, às 21:20h. p. 12 e 25).

29 BELTRAN, Jordí Ferrer. La valoración racional de la prueba. Marcial Pons: Madri, 2007. p. 120-125. 
deles, a segunda supõe que a decisão sobre o fato parte de hipóteses globais, considerando as stories que as partes contam tal como uma novela.

A decisão judicial dotada de racionalidade e que atende à garantia esculpida no art. 93, IX, da Constituição Federal é, portanto, a que se baseia numa narração congruente a respeito dos fatos que resultam testados, provados e correspondentes àqueles previstos como suposto de fato da norma jurídica aplicada ao caso em julgamento.

\section{RAZÃO DO PROCESSO E RAZÃO NO PROCESSO NO CPC/15}

Este tópico tratará de apresentar alguns dispositivos do Código de Processo Civil de 2015 que retratam as exigências de razão no processo e respeitam as razões do processo. Não se trata de apontar tais dispositivos como os únicos reveladores desta vocação do Código, mas apenas de ilustrá-la a partir de artigos que são aplicados com frequência na rotina processual, em uma concepção publicística de processo.

5.1. Artigo 77. Além de outros previstos neste Código, são deveres das partes, de seus procuradores e de todos aqueles que de qualquer forma participem do processo: I expor os fatos em juízo conforme a verdade.

Se é dever dos atores processuais expor os fatos conforme a verdade, considerandose litigante de má-fé aquele que a altera (artigo 80, II), intui-se que o Código de Processo Civil se baseia em concepção correspondentista, não se contentando com o acolhimento de versões apresentadas pelas partes que sejam meramente coerentes ou justificáveis com os elementos dos autos. Esta posição é reforçada quando se lembra que tal dever não é dado isolado na lei, mas concebido em um contexto mais amplo de cooperação e lealdade processuais (artigos $6^{\circ}$ a $8^{\circ}$ ) e de comunhão das provas coligidas aos autos (artigos 369 a 371). Tal cenário remonta ao pensamento segundo o qual o processo não funciona para, ao final, acolher uma ou outra versão pré-fabricada, mas sim para a (possível) reconstrução dialética dos fatos ocorridos, da qual será possível a afirmação do direito.

Evidente que os fatos são expostos segundo a visão do interessado, ou seja, a partir de sua posição. Por isso, o não acolhimento de sua tese ou da leitura que fez dos fatos não é 
capaz, por si só, de implicar a declaração de litigância de má-fé ou de motivação ilícita da sua pretensão. O que o Código busca evitar é que os fatos sejam objetivamente alterados, seja para omiti-los, emendá-los ou inventá-los ${ }^{30}$, exatamente porque sua visão correspondentista não se contenta com que o direito seja declarado tendo por base fatos falseados.

5.2. Artigo 142. Convencendo-se, pelas circunstâncias, de que autor e réu se serviram do processo para praticar ato simulado ou conseguir fim vedado por lei, o juiz proferirá decisão que impeça os objetivos das partes, aplicando, de ofício, as penalidades da litigância de má-fé.

Esta disposição reforça o que se argumentou no tópico anterior a respeito da visão correspondentista do Código de Processo Civil, e isso mesmo quando as partes, em princípio as maiores interessadas no resultado do processo, trabalham em harmonia para retratar situação não condizente com a verdade no mundo dos fatos.

Como escrevem Marinoni, Arenhart e Mitidiero, caracteriza-se uma simulação "quando as partes vão a juízo afirmando um litígio aparente, que na realidade não existe, a fim de conferir ou transmitir direitos simuladamente" 31 . Ao instar o juiz a impedir o intento simulado das partes, a legislação processual reforça sua predileção pela construção de decisão que guarde correspondência com os fatos acontecidos, rejeitando elaborações meramente coerentes ou justificadas em cenário idealizado nos autos, mesmo que seja esta a vontade das partes e mesmo que o tema da "lide" verse sobre direitos disponíveis, já que não há ressalva do Código a respeito de sua natureza. Esta empreitada encontra ressonância também no artigo 966, III, do Código, no que permite o ajuizamento de ação rescisória para evitar a chancela estatal à construção das partes que não corresponda de fato e de direito com o acontecido no mundo dos fatos.

30 ALVIM, Teresa Arruda; DIDIER JR., Fredie; TALAMINI, Eduardo; DANTAS, Bruno (coord). Breves comentários ao novo código de processo civil. São Paulo: Revista dos Tribunais, 2015. p. 273.

31 MARINONI, Luiz Guilherme; ARENHART, Sérgio Cruz; MITIDIERO, Daniel. Novo código de processo civil comentado. 3. Ed. São Paulo: Revista dos Tribunais, 2017. p. 176. 
5.3. Artigo 371. O juiz apreciará a prova constante dos autos, independentemente do sujeito que a tiver promovido, e indicará na decisão as razões da formação de seu convencimento

Este dispositivo chama a atenção pelo que ele não tem. É que ele difere do seu correspondente no Código anterior (artigo 131), sobretudo, pela supressão da palavra "livre" ao se referir à atividade judicial de apreciação da prova.

Por certo que a sistemática vigente até então não pretendia admitir atuação jurisdicional desapegada dos elementos de prova constantes dos autos e alheia à construção racional da decisão, mas apenas afastar a adoção de um sistema de provas legais ou tarifadas.

A retirada da palavra "livre" estaria a indicar a reafirmação contra posturas voluntaristas do juiz, aclamando a prevalência da racionalidade da justificação das decisões judiciais. Sem ignorar a margem de discricionariedade na formação da convicção judicial, este movimento do legislador visa à objetivação e maior controle do raciocínio probatório do juiz na valoração e justificação da sentença judicial que dá por provada uma hipótese ${ }^{32}$.

\subsection{Artigo 373. O ônus da prova incumbe (...)}

A regra do ônus da prova, além de remeter às limitações epistêmicas do funcionamento do processo, apresenta um norte para garantir a racionalidade e previsibilidade da decisão judicial.

O ordenamento processual indica o caminho para a solução de casos duvidosos - cujo raciocínio probatório não foi capaz de atingir o standard necessário para a prolação da decisão -, em vista da vedação ao non liquet. Para esta situação, a ordem jurídica não considera falso o fato alegado por uma ou outra parte, tampouco faz surgir uma presunção acerca de sua falsidade, mas sustenta uma regra capaz de sustentar validamente uma decisão judicial em caso de dúvida, regra que, em essência, repousa no pensamento corrente segundo o qual cabe àquele que alega um fato provar sua ocorrência.

\footnotetext{
${ }^{32}$ MARANHÃO, Clayton de Albuquerque. Standards de prova no processo civil brasileiro. Revista Judiciária do Paraná, Curitiba, Vol. 17, p. 221-258. Maio, 2019. p. 223.
} 
Como observa Mitidiero, a regra do ônus da prova afasta a aleatoriedade que permitiria ao juiz, sem a segurança conferida na prova e pela prova, escolher uma solução para o caso apenas com base em suas convicções íntimas ou predileções, conferindo segurança jurídica em relação ao resultado do processo diante de um resultado duvidoso ${ }^{33}$. A lei processual, com a regra do ônus da prova, cria um critério de desempate previamente à decisão em caso de dúvida, permitindo controle pelas partes, racionalidade e objetividade da atuação judicial.

5.5 Art. 479. O juiz apreciará a prova pericial de acordo com o disposto no art. 371, indicando na sentença os motivos que o levaram a considerar ou a deixar de considerar as conclusões do laudo, levando em conta o método utilizado pelo perito.

O Código de Processo Civil reclama análise racional e acolhimento justificado mesmo da prova pericial, que por envolver temas de áreas do conhecimento alheias à formação dos atores processuais muitas vezes acaba sendo acolhida pelo julgador como elemento capaz de atingir um standard probatório absoluto, conferindo espécie de caráter vinculante ao seu conteúdo pelo só fato de possuir ares de tecnicidade e ciência.

Carmen Vázquez Rojas alerta para o equívoco de tomar a cientificidade da prova como fator suficiente de justificação de sua fiabilidade a ponto de colocá-la em um pedestal epistêmico. Baseada em Susan Haack, Vázquez destaca o problema do cientificismo, ou seja, da incapacidade de reconhecer a falibilidade, limitações e perigos potenciais da empreitada científica ${ }^{34}$.

Bem por isso, a estrutura de produção e acolhimento da prova pericial concebida pelo Código reclama o aporte de dados objetivos para evidenciar o embasamento técnico do trabalho do perito, o método utilizado e sua aceitação pela comunidade científica (artigo 473 CPC) a fim de possibilitar controle judicial racional sobre seu conteúdo e confiabilidade, sob

33 MITIDIERO, Daniel. O ônus da prova e seus inimigos. Revista de Processo [Online], Vol. 306. Agosto, 2020. p. 7-8.

34 ROJAS, Carmen Vázquez. De la prueba científica a la prueba pericial. Madri: Marcial Pons, 2015. p. 83-91. 
pena de restar configurado vício de fundamentação da decisão que toma aquela prova por norte ${ }^{35}$.

\section{CONCLUSÃO}

O amplo acesso à jurisdição garantido pela Constituição Federal e a notória judicialização da vida conferem traços mais fortes à atuação judicial e exigem cada vez mais cuidados para um funcionamento adequado do processo. Se a definição do que é o Direito e o estabelecimento de rumos das mais variadas questões passam pela atuação jurisdicional, é preciso que esta seja passível de escrutínio pelas partes envolvidas e pelo público e que se compreenda sua relação com o mundo fora dos autos.

Faz-se necessário que os passos dados no processo trilhem o tanto quanto possível o caminho do ocorrido no mundo dos fatos, do que se exige atuação do juiz que não se contente em construir decisões que se esgotem e se satisfaçam em discursos coerentes em si ou neles mesmos justificados. A razão de existir do processo exige o exercício da razão no processo e a construção do discurso a partir da prova dos autos e da correspondência entre os enunciados de fato e os acontecimentos no mundo, tendo a verdade como ideal regulatório.

Não é possível tornar a atividade jurisdicional totalmente imune às construções subjetivas do juiz; afinal, como ser humano, o julgador é influenciando por suas circunstâncias pessoais na análise dos fatos e na compreensão do Direito. O que a razão do processo refuta é que percepções subjetivas não sindicáveis e o senso pessoal de justiça sejam colocados como instrumentos para a construção de decisões sobre a existência de direitos subjetivos e o significado do direito objetivo.

Admitir que a atuação judicial seja circunscrita ao que a íntima convicção do julgador da vez entende como justo e acertado, independentemente da correspondência com a realidade, da prova produzida e de argumentos sustentados na razão, significa, em última análise, reduzir o papel do processo a algo muito aquém daquilo para o que foi desenhando constitucionalmente.

35 ALMEIDA, Diogo Assumpção Rezende de. A prova pericial no processo civil. O controle da ciência e a escolha do perito. São Paulo: Renovar, 2011. p. 153-156. 


\section{REFERÊNCIAS:}

AARNIO, Aulis. Lo racional como razonable. Un tratado sobre la justificación jurídica. Madrid: Centro de Estudios Constitucionales, 1991.

ABELLAN, Marina Gascon. Los hechos en el derecho. Bases argumentales de la prueba. 3. Ed. Marcial Pons: Madri, 2010.

ACATINO, Daniella. Teoría de la prueba: ¿somos todos "racionalistas" ahora? Revus [Online], n. 39 (Dezembro, 2019).

ALMEIDA, Diogo Assumpção Rezende de. A prova pericial no processo civil. O controle da ciência e a escolha do perito. São Paulo: Renovar, 2011.

ALVIM, Teresa Arruda; DIDIER JR., Fredie; TALAMINI, Eduardo; DANTAS, Bruno (coord). Breves comentários ao novo código de processo civil. São Paulo: Revista dos Tribunais, 2015.

ATIENZA, Manuel. Pragmatismo jurídico: La propuesta de Susan Haack. Disponível em $<$ https://dfddip.ua.es/es/documentos/pragmatismo-

juridico.pdf?noCache=1538988924734> Acesso em 04 de julho de 2020, às 11:09h.

BELTRAN, Jordí Ferrer. La valoración racional de la prueba. Marcial Pons: Madri, 2007.

FISS, Owen. Contra o acordo. In: SALLES, Carlos Alberto de (coord.). Um novo Processo

Civil: estudos norte-americanos sobre Jurisdição, Constituição e sociedade. Tradução Daniel Porto Godinho da Silva e Melina de Medeiros Rós. São Paulo: Editora Revista dos Tribunais, 2004.

LAGIER, Daniel González. Apuntes sobre prueba y argumentacion jurídica. Disponível em <http://rua.ua.es/dspace/handle/10045/37145>. Acesso em 07 de julho de 2020, às $21: 20 \mathrm{~h}$.

Tres modos de razonar sobre hechos (y algunos problemas sobre la prueba judicial planteados a partir de ellos). In VÁZQUEZ, Carmen. Hechos y razonamiento probatório. México DF: Editorial CEJI, 2018.

MARANHÃO, Clayton de Albuquerque. Standards de prova no processo civil brasileiro. Revista Judiciária do Paraná, Curitiba, Vol. 17, p. 221-258. (Maio, 2019). 
MARINONI, Luiz Guilherme; ARENHART, Sérgio Cruz; MITIDIERO, Daniel. Novo código de processo civil comentado. 3. Ed. São Paulo: Revista dos Tribunais, 2017.

MITIDIERO, Daniel. O ônus da prova e seus inimigos. Revista de Processo [Online], Vol. 306. (Agosto, 2020).

OLIVEIRA, Carlos Alberto Alvaro de. Do formalismo no processo civil. 2. Ed. São Paulo: Saraiva, 2010.

OLIVEIRA, Paulo Mendes de. Segurança jurídica e processo. Da rigidez à flexibilização processual. São Paulo: RT, 2018.

RAGONE, Álvaro Perez. El impaco entre lo sustantivo y lo procesal: el puente de la justicia procedimental. In: ARENHART, Sérgio Cruz; MITIDIERO, Daniel (coord.). O Processo civil entre a técnica processual e a tutela dos direitos: estudos em homenagem a Luiz Guilherme Marinoni. São Paulo: Editora Revista dos Tribunais, 2017. p. 21-38.

ROJAS, Carmen Vázquez. De la prueba científica a la prueba pericial. Madri: Marcial Pons, 2015.

SUMMERS, Robert. S. Evaluating and improving legal process. A plea for process values. In Cornell Law Review. Vol. 60. Nov/1974. p. 1-52.

TARUFFO, Michele. Uma simples verdade: o juiz e a construção dos fatos. Tradução de Vitor de Paula Ramos. São Paulo: Marcial Pons, 2016.

La prueba de los hechos. Tradução para o espanhol de Jordi Beltran Ferrer. Madrid: Editorial Trotta, 2002.

TUZET, Giovanni. Filosofia della prova giuridica. 2. Ed. Torino: G. Giappichelli Editore, 2016.

TWINING, William. Rethinking evidence. Exploratory essays. 2. Ed. Cambridge: Cambridge University Press, 2006.

WALDRON, Jeremy. The rule of law and the importance of procedure. In. FELMING, J. Gettíng to the rule of law. New York: New York U. Press, Nomos, 2011. 